\title{
Judicious Use of Antibiotics and Radiologic Imaging in Diagnosis and Management of Pediatric Upper Respiratory Tract Infections
}

\author{
Preeti Jaggi ${ }^{1}$ \\ ${ }^{1}$ Division of Infectious Diseases, Department of Pediatrics, \\ Nationwide Children's Hospital, Columbus, Ohio, United States \\ J Pediatr Infect Dis 2019;14:20-23.
}

\begin{abstract}
Address for correspondence Preeti Jaggi, MD, Division of Infectious Diseases, Department of Pediatrics, Nationwide Children's Hospital, 700 Children's Drive, Columbus, OH 43205, United States (e-mail: Preeti.jaggi@nationwidechildrens.org).
\end{abstract}
Abstract
Keywords
- CT scan
- antimicrobial stewardship
- deep neck infection

A considerable amount of effort has been put into the reduction of the overuse of antibiotics and reduction in radiographic studies in the pediatric population. Infections within the ear, nose, and throat and in cervical regions are a frequent source of antibiotic use in children. Quality improvement projects creating clear care pathways have been important to delineate which imaging may be most helpful.

\section{Judicious Use of Antibiotics in Pediatrics}

Antibiotics are not only life-saving drugs, but also carry significant risk and are significantly overused. It is estimated that 30 to $50 \%$ of antimicrobials are inappropriately prescribed in the inpatient setting and at least $30 \%$ are inappropriate in the outpatient setting. ${ }^{1}$ Antibiotics are also the most common cause of adverse drug events in children, accounting for 7 of the top 10 drugs leading to pediatric-related emergency room visits. ${ }^{2}$ Reducing inappropriate antimicrobial use is critical to prevent further bacterial resistance. The National Action Plan for Combating Antibiotic-Resistant Bacteria has set the goal of reducing inappropriate antibiotic use in the outpatient setting by $50 \%$ by $2020 .^{3}$ This goal is especially relevant to children. A large proportion of antibiotic consumption in the United States is provided to children, with the highest rates of prescribing to children $\leq 2$ years of age. Children will more likely suffer the consequences of antimicrobial resistance that results from societal and repeated personal exposure to antimicrobials as they reach adulthood. ${ }^{4}$

There is considerable heterogeneity in the amount and frequency of the use of antibiotics. They are prescribed more frequently in the United States than in Europe, ${ }^{5}$ and within the United States, there are geographic differences in frequency of prescribing. ${ }^{6}$ Antibiotics are most often prescribed for respiratory tract infections. ${ }^{7}$ Antibiotic prescribing rates for acute respiratory tract infections among a group of practices in Philadelphia ranged from 18 to $36 \%$ of visits, ${ }^{8}$ demonstrating

received

April 10, 2018

accepted after revision

May 18, 2018

published online

July 6, 2018
Otorhinolaryngology; Guest Editors: Kris R. Jatana, MD; Jeffrey C. Rastatter, MD. that considerable heterogeneity exists among practitioners in prescribing antibiotics when a child presents with upper respiratory tract symptoms. In an analysis of 2014 healthcare claims from a pediatric accountable care organization, we found that $18.5 \%$ of antibiotics dispensed among $\sim 250,000$ clinical encounters of relatively healthy children with upper respiratory tract symptoms in 2014 were in association with diagnostic codes for viral upper respiratory tract infection only. Even among diagnoses generally accepted to require antibiotics, the diagnosis itself may not be accurate, and there is little feedback to clinicians in practice. For example, pediatricians and pediatric residents often misdiagnosed otitis media with effusion from acute otitis media when presented with a video recording of otoscopic examinations of the tympanic membrane, ${ }^{9,10}$ raising concern of misdiagnosis prompting potentially unnecessary antibiotics. Another strategy to gauge the accuracy of the diagnosis may be the frequency with which it is made. In the analysis of prescribing patterns from a pediatric accountable care organization affiliated with our institution, we also found a tremendous heterogeneity in the rates of antibiotic dispensation in association with diagnostic codes solely for sinusitis of 2.2 to $22 \%$, which is a clinical diagnosis primarily based on history. ${ }^{11}$ The rate of sinusitis complicating an upper respiratory infection in the 4 - to 7 -year-old age group was found to be only $8.8 \%$ in a recent prospective study, ${ }^{12}$ and the discrepancy in the rates of diagnosis indicates that sinusitis may be over diagnosed in the community.
Copyright (c) 2019 by Georg Thieme Verlag KG, Stuttgart · New York
DOI https://doi.org/ 10.1055/s-0038-1661388. ISSN 1305-7707. 
It is estimated that $30 \%$ of outpatient antibiotic prescriptions are unnecessary. ${ }^{1}$ Tracking and reporting antibiotic use is considered one of the core elements of outpatient antimicrobial stewardship, ${ }^{13}$ and feedback to prescribers on a regular basis has been shown to decrease broad-spectrum and inappropriate prescribing. ${ }^{14,15}$ Further efforts are needed to provide feedback to prescribers on the accuracy and appropriateness of the clinical diagnoses made that prompted antibiotic prescribing.

Beyond the risk of bacterial resistance and side effects, antibiotics may have other consequences to children, with concern raised that antibiotic exposure(s) may increase the risk for diabetes, ${ }^{16}$ autoimmune illness, ${ }^{17}$ asthma, and allergies. ${ }^{18}$ It is imperative that clinicians weigh both short- and long-term risks of antibiotics before prescribing.

\section{Judicious Use of Computed Tomography in Pediatrics}

It is estimated that more 4 million computed tomography (CT) scans are performed in children per year. Potential adverse events with CT scan exposure in children are radiation-associated malignancy, incidental findings that may prompt additional testing, and increased cost. Radiation exposure in young children, particularly, can be associated with potential harm. It is estimated that one case of leukemia is estimated to result from 5,250 CT scans in this age group, ${ }^{19}$ with the highest risk being for scans of the head.

Use of CT scans in tertiary care pediatric hospitals varies widely. ${ }^{20}$ The use of clinical pathways have been beneficial to reduce the use of CT scans in head trauma, ${ }^{21-24}$ and alternative use of ultrasound has been beneficial to reduce radiation exposure in appendicitis, ${ }^{25-27}$ but such pathways in head and neck infections have not been as widely implemented. We will discuss in this review strategies to potentially reduce CT scan use while evaluating for deep neck space infection, lymphadenitis, and acute mastoiditis.

Diagnostic imaging in deep neck space infections-parapharyngeal, retropharyngeal, and peritonsillar infections (henceforth called deep neck infection, or DNI)-can be associated with significant morbidity and mortality, especially when the diagnosis is delayed. ${ }^{28,29}$ Some children may improve with antimicrobials alone, ${ }^{30-32}$ though some suggest an initial surgical approach for parapharyngeal and retropharyngeal infection. ${ }^{33,34}$ Both acute lymphadenitis and parapharyngeal infection can be on the differential diagnosis in those presenting with neck swelling. Tonsillar ultrasound may be used to evaluate specifically peritonsillar infection and may sometimes detect a parapharyngeal infection as well. ${ }^{35}$

We reviewed our single-center experience to identify the factors associated with medical management alone for DNI. ${ }^{36}$ During the study period, 130 patients who were previously healthy and had no recent trauma or surgery were identified, and 43\% underwent surgical intervention. Cultures demonstrating methicillin-resistant Staphylococcus aureus (MRSA) were documented in four patients; one of these patients presented septic shock. Multivariate analysis for the outcome of medical management alone was per- formed; older patients had a significantly higher probability of treatment with antimicrobials alone, independent of other covariates. All patients in our series underwent CT scan evaluation, with $21 \%$ undergoing a second CT scan evaluation during their hospitalization, raising some concern that CT scans may be overused in the evaluation of these children.

Several studies have suggested that younger children have increased risk for complications, such as mediastinitis and also for infection due to MRSA. ${ }^{37,38}$ The aggregate data suggest that children under the age of 2 years should be monitored more closely for complications, for presence for MRSA infection, and for the need for surgical intervention.

We combined factors associated with decreased likelihood for need of surgical intervention and clinical presentation to create a pathway for evaluation and management of children with suspected DNI or lymphadenitis. For the older, non-ill-appearing patient who has no respiratory distress, a CT scan may provide more useful information when performed after the first 24 to 48 hours of medical therapy if the child is not improving, as more than half of children in our cohort improved with antimicrobial therapy alone. A proposed clinical pathway is shown in - Fig. 1.

Another potential disadvantage to CT scan use is delay in surgical intervention. In a case-control study of treatment for peritonsillar infection, the mean time to either a bedside or surgical procedure was 493 minutes in those who received a CT scan compared with 175 minutes in those who did not receive a CT scan. There was no association between the use of CT scan and performance of a procedure. ${ }^{39}$ We do not recommend routine use of CT scans in this population, as the presentation and physical examination are appropriate for diagnosis.

Acute mastoiditis is most common in young children, with approximately one-third of cases occurring in those less than 24 months. ${ }^{40}$ Some patients may present with purulent extension into the intracranial space (e.g., epidural abscess) or extracranial areas, (e.g., osteomyelitis or Bezold abscess). CT is useful to define bony changes and intracranial/extracranial abscess and thrombosis. However, the most common complication is subperiosteal abscess, ${ }^{41}$ and intracranial complication from mastoiditis is estimated to be less than $10 \%,{ }^{42}$ so some advocate waiting for image unless there are neurologic changes and/or signs indicative of a focal abscess. Magnetic resonance imaging may be preferable because of the lack of radiation and because it is superior in definition of intracranial complications, but often it cannot be obtained in a timely manner, and/or the children may require sedation, which carries other risks. One approach could be similar to that published in an Israeli cohort, ${ }^{42}$ where CT scans were obtained in only $22 \%$ of 86 children presenting with symptoms concerning for acute mastoiditis. Reasons prompting imaging were suspected subperiosteal abscess, lack of appropriate improvement, and/or focal neurologic signs.

\section{Conclusion}

Access to both antibiotics and CT scans is readily available in the United States, but judicious use of these entities is critical 


\section{Suspected Non-Traumatic Neck Infection Protocol *}

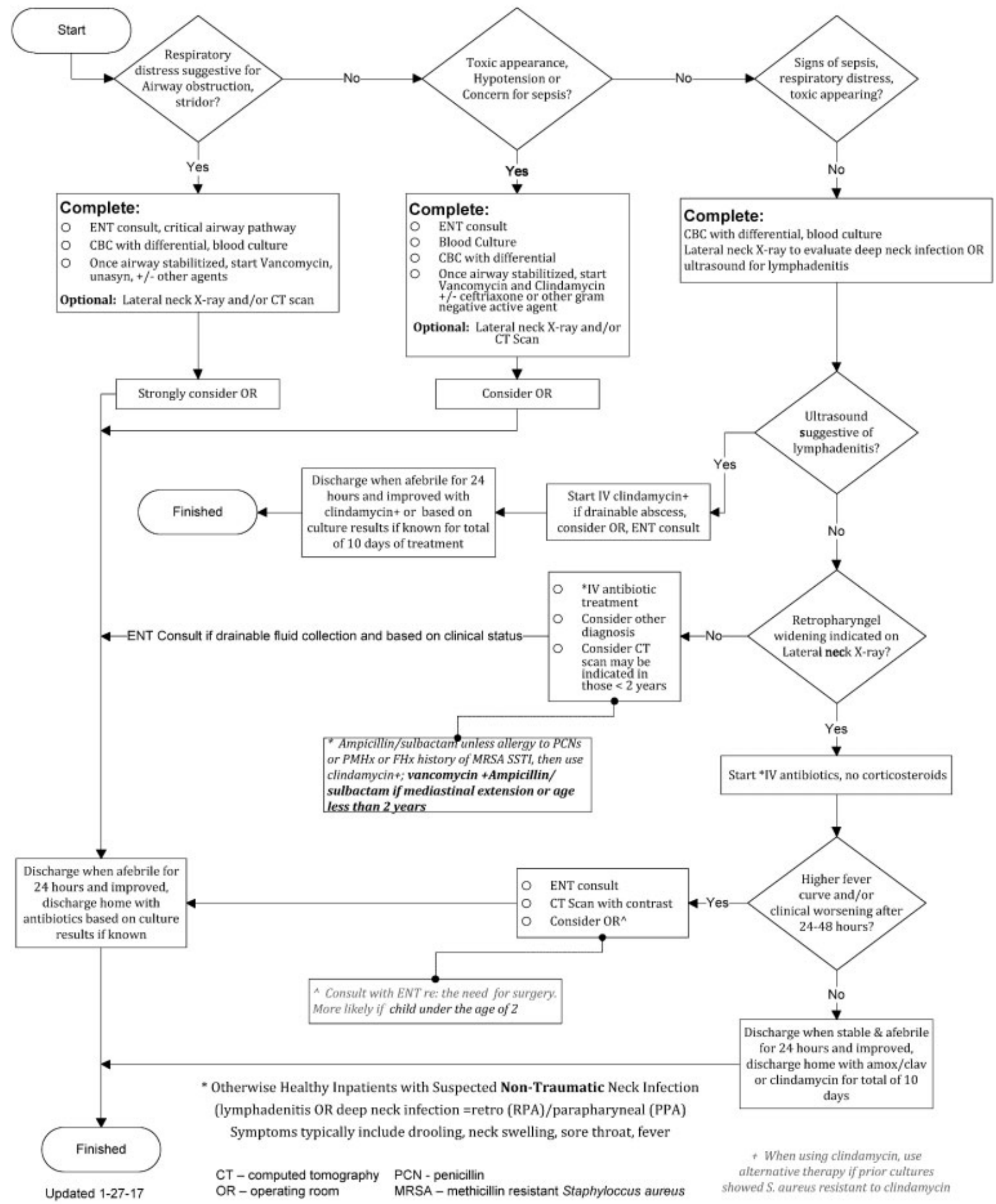

Fig. 1 Suspected nontraumatic neck infection protocol. CBC, complete blood count; ENT, ear, nose, and throat; IV, intravenous.

for preventing harm to children. A more evidence-based and select use is in the best interest of our pediatric patients.

\section{Conflict of Interest}

None declared.

\section{References}

1 Fleming-Dutra KE, Hersh AL, Shapiro DJ, et al. Prevalence of inappropriate antibiotic prescriptions among US ambulatory care visits, 2010-2011. JAMA 2016;315(17):1864-1873

2 Shehab N, Lovegrove MC, Geller AI, Rose KO, Weidle NJ, Budnitz DS. US emergency department visits for outpatient adverse drug events, 2013-2014. JAMA 2016;316(20):2115-2125 
3 The White House. National action plan for combating antibioticresistant bacteria. Available at: https://www.whitehouse.gov/ sites/default/files/docs/national_action_plan_for_combating_antibotic-resistant_bacteria.pdf. Accessed January 15, 2018

4 Paschke AA, Zaoutis T, Conway PH, Xie D, Keren R. Previous antimicrobial exposure is associated with drug-resistant urinary tract infections in children. Pediatrics 2010;125(04):664-672

5 Goossens H, Ferech M, Coenen S, Stephens P; European Surveillance of Antimicrobial Consumption Project Group. Comparison of outpatient systemic antibacterial use in 2004 in the United States and 27 European countries. Clin Infect Dis 2007;44(08):1091-1095

6 Hicks LA, Bartoces MG, Roberts RM, et al. US outpatient antibiotic prescribing variation according to geography, patient population, and provider specialty in 2011. Clin Infect Dis 2015;60(09):1308-1316

7 Hersh AL, Shapiro DJ, Pavia AT, Shah SS. Antibiotic prescribing in ambulatory pediatrics in the United States. Pediatrics 2011;128 (06):1053-1061

8 Gerber JS, Prasad PA, Russell Localio A, et al. Variation in antibiotic prescribing across a pediatric primary care network. J Pediatric Infect Dis Soc 2015;4(04):297-304

9 Pichichero ME. Diagnostic accuracy of otitis media and tympanocentesis skills assessment among pediatricians. Eur J Clin Microbiol Infect Dis 2003;22(09):519-524

10 Pichichero ME. Diagnostic accuracy, tympanocentesis training performance, and antibiotic selection by pediatric residents in management of otitis media. Pediatrics 2002;110(06):1064-1070

11 Wald ER, Applegate KE, Bordley C, et al; American Academy of Pediatrics. Clinical practice guideline for the diagnosis and management of acute bacterial sinusitis in children aged 1 to 18 years. Pediatrics 2013;132(01):e262-e280

12 DeMuri GP, Gern JE, Moyer SC, Lindstrom MJ, Lynch SV, Wald ER. Clinical features, virus identification, and sinusitis as a complication of upper respiratory tract illness in children ages 4-7 years. J Pediatr 2016;171:133-9.e1

13 Sanchez GV, Fleming-Dutra KE, Roberts RM, Hicks LA. Core elements of outpatient antibiotic stewardship. MMWR recommendations and reports. Morbidity Mortality Weekly Report Recommendations Reports 2016;65:1-12

14 Gerber JS, Prasad PA, Fiks AG, et al. Effect of an outpatient antimicrobial stewardship intervention on broad-spectrum antibiotic prescribing by primary care pediatricians: a randomized trial. JAMA 2013;309(22):2345-2352

15 Meeker D, Knight TK, Friedberg MW, et al. Nudging guidelineconcordant antibiotic prescribing: a randomized clinical trial. JAMA Intern Med 2014;174(03):425-431

16 Clausen TD, Bergholt T, Bouaziz O, et al. Broad-Spectrum antibiotic treatment and subsequent childhood type 1 diabetes: a Nationwide Danish Cohort Study. PLoS One 2016;11(08):e0161654

17 Horton DB, Scott FI, Haynes K, et al. Antibiotic Exposure and Juvenile Idiopathic Arthritis: A Case-Control Study. Pediatrics 2015;136(02):e333-e343

18 Hirsch AG, Pollak J, Glass TA, et al. Early-life antibiotic use and subsequent diagnosis of food allergy and allergic diseases. Clin Exp Allergy 2017;47(02):236-244

19 Miglioretti DL, Johnson E, Williams A, et al. The use of computed tomography in pediatrics and the associated radiation exposure and estimated cancer risk. JAMA Pediatr 2013;167(08):700-707

20 Lodwick DL, Cooper JN, Kelleher KJ, Brilli R, Minneci PC, Deans KJ. Variation in utilization of computed tomography imaging at tertiary pediatric hospitals. Pediatrics 2015;136(05):e1212-e1219

21 Atabaki SM, Hoyle JD Jr, Schunk JE, et al. Comparison of prediction rules and clinician suspicion for identifying children with clinically important brain injuries after blunt head trauma. Acad Emerg Med 2016;23:566-575
22 Stanley RM, Hoyle JD Jr, Dayan PS, et al. Emergency department practice variation in computed tomography use for children with minor blunt head trauma. J Pediatr 2014;165:1201-1206

23 Nigrovic LE, Schunk JE, Foerster A, et al; Traumatic Brain Injury Group for the Pediatric Emergency Care Applied Research Network. The effect of observation on cranial computed tomography utilization for children after blunt head trauma. Pediatrics 2011; 127(06):1067-1073

24 Kuppermann N, Holmes JF, Dayan PS, et al; Pediatric Emergency Care Applied Research Network (PECARN). Identification of children at very low risk of clinically-important brain injuries after head trauma: a prospective cohort study. Lancet 2009;374(9696):1160-1170

25 Nielsen JW, Boomer L, Kurtovic K, et al. Reducing computed tomography scans for appendicitis by introduction of a standardized and validated ultrasonography report template. J Pediatr Surg 2015;50(01):144-148

26 Callahan MJ, Anandalwar SP, MacDougall RD, et al. Pediatric CT dose reduction for suspected appendicitis: a practice quality improvement project using artificial gaussian noise-part 2, clinical outcomes. Am J Roentgenol 2015;204(03):636-644

27 Bachur RG, Hennelly K, Callahan MJ, Monuteaux MC. Advanced radiologic imaging for pediatric appendicitis, 2005-2009: trends and outcomes. J Pediatr 2012;160(06):1034-1038

28 Philpott CM, Selvadurai D, Banerjee AR. Paediatric retropharyngeal abscess. J Laryngol Otol 2004;118(12):919-926

29 Cabrera CE, Deutsch ES, Eppes S, et al. Increased incidence of head and neck abscesses in children. Otolaryngol Head Neck Surg 2007; 136(02):176-181

30 Sichel JY, Dano I, Hocwald E, Biron A, Eliashar R. Nonsurgical management of parapharyngeal space infections: a prospective study. Laryngoscope 2002;112(05):906-910

31 Craig FW, Schunk JE. Retropharyngeal abscess in children: clinical presentation, utility of imaging, and current management. Pediatrics 2003;111(6 Pt 1):1394-1398

32 Broughton RA. Nonsurgical management of deep neck infections in children. Pediatr Infect Dis J 1992;11(01):14-18

33 Lalakea Ml, Messner AH. Retropharyngeal abscess management in children: current practices. Otolaryngol Head Neck Surg 1999; 121(04):398-405

34 Kirse DJ, Roberson DW. Surgical management of retropharyngeal space infections in children. Laryngoscope 2001;111(08):1413-1422

35 Bandarkar AN, Adeyiga AO, Fordham MT, Preciado D, Reilly BK. Tonsil ultrasound: technical approach and spectrum of pediatric peritonsillar infections. Pediatr Radiol 2016;46(07):1059-1067

36 Bolton M, Wang W, Hahn A, Ramilo O, Mejias A, Jaggi P. Predictors for successful treatment of pediatric deep neck infections using antimicrobials alone. Pediatr Infect Dis J 2013;32(09):1034-1036

37 Abdel-Haq N, Quezada M, Asmar BI. Retropharyngeal abscess in children: the rising incidence of methicillin-resistant Staphylococcus aureus. Pediatr Infect Dis J 2012;31(07):696-699

38 Brown NK, Hulten KG, Mason EO, Kaplan SL. Staphylococcus aureus retropharyngeal abscess in children. Pediatr Infect Dis J 2015;34(04):454-456

39 Grant MC, Guarisco JL. Association between computed tomographic scan and timing and treatment of peritonsillar abscess in children. JAMA Otolaryngol Head Neck Surg 2016;142(11):1051-1055

40 Ghaffar FA, Wördemann M, McCracken GH Jr. Acute mastoiditis in children: a seventeen-year experience in Dallas, Texas. Pediatr Infect Dis J 2001;20(04):376-380

41 Ghadersohi S, Young NM, Smith-Bronstein V, Hoff S, Billings KR. Management of acute complicated mastoiditis at an urban, tertiary care pediatric hospital. Laryngoscope 2017;127(10):2321-2327

42 Marom T, Roth Y, Boaz M, et al. Acute mastoiditis in children: necessity and timing of imaging. Pediatr Infect Dis J 2016;35(01):30-34 